Published in final edited form as:

Crit Care Med. 2014 July ; 42(7): e525-e533. doi:10.1097/CCM.0000000000000300.

\title{
The selective $V_{1 a}$ receptor agonist selepressin (FE 202158) blocks vascular leak in ovine severe sepsis
}

\author{
Marc O. Maybauer, MD, PhD, EDIC, FCCP\#1,2 Dirk M. Maybauer, MD, PhD ${ }^{\# 1,2}$, Perenlei \\ Enkhbaatar, MD, PhD ${ }^{\# 1}$, Régent Laporte, DVM, MSc, PhD ${ }^{\# 3}$, Halina Wiśniewska, MS $^{3}$, Lillian \\ D. Traber, RN ${ }^{1}$, ChiiDean Lin, $\mathrm{PhD}^{4}$, Juanjuan Fan, $\mathrm{PhD}^{4}$, Hal K. Hawkins, MD, PhD ${ }^{5}$, Robert \\ A. Cox, $\mathrm{PhD}^{5}$, Kazimierz Wiśniewski, $\mathrm{PhD}^{3}$, Claudio D. Schteingart, $\mathrm{PhD}^{3}$, Donald W. \\ Landry, $\mathrm{MD}, \mathrm{PhD}^{6}$, Pierre J.-M. Rivière, $\mathrm{PhD}^{3}$, and Daniel L. Traber, PhD, FCCM ${ }^{1}$ \\ ${ }^{1}$ Investigational Intensive Care Unit, Department of Anesthesiology, University of Texas Medical \\ Branch, Galveston, Texas, United States of America \\ ${ }^{2}$ Department of Anaesthesia and Intensive Care, Philipps University of Marburg, Marburg, \\ Germany \\ ${ }^{3}$ Ferring Research Institute, Inc., San Diego, California, United States of America \\ ${ }^{4}$ Department of Mathematics and Statistics, San Diego State University, San Diego, California, \\ United States of America \\ ${ }^{5}$ Department of Pathology, University of Texas Medical Branch, Galveston, Texas, United States \\ of America \\ ${ }^{6}$ Department of Medicine, Columbia University, New York City, New York, United States of \\ America \\ \# These authors contributed equally to this work.
}

\section{Abstract}

Objective-To determine if the selective vasopressin type 1a receptor $\left(\mathrm{V}_{1 \mathrm{a}} \mathrm{R}\right)$ agonist selepressin (FE 202158) is as effective as the mixed $V_{1 a} / V_{2}$ receptor $\left(V_{1 a} R / V_{2} R\right)$ agonist vasopressor hormone arginine vasopressin (AVP) when used as a titrated first-line vasopressor therapy in an ovine model of Pseudomonas aeruginosa pneumonia-induced severe sepsis.

Design-Prospective, randomized, controlled laboratory experiment.

Setting-University animal research facility.

\footnotetext{
Address for reprints: Régent Laporte Telephone: 858-657-1543 Fax: 858-657-1500 regent.laporte @ ferring.com. Conflicts of Interest

M.O.M., D.M.M., P.E., H.K.W., R.A.C., L.D.T., and D.L.T. are/were employees of the University of Texas Medical Branch at Galveston, which was contracted by the Ferring Research Institute to conduct the study reported here.

C.-D.L. and J.F. are employees of Forestat Consulting Group, LLC, which was contracted by the Ferring Research Institute to conduct the statistical analysis of the study reported here.

R.L., H.W., K.W., C.D.S., P.J.-M.R. are/were employees of the Ferring Research Institute.

D.W.L. and D.L.T. were consultants for the Ferring Research Institute.

Copyright Form Disclosures:

The remaining authors have disclosed that they do not have any potential conflicts of interest.
} 
Subjects—Forty-five chronically instrumented sheep.

Interventions-Sheep were anesthetized, insufflated with cooled cotton smoke via tracheostomy, and $P$. aeruginosa were instilled into their airways. They were then placed on assisted ventilation, awakened, and resuscitated with lactated Ringer's solution titrated to maintain hematocrit $\pm 3 \%$ from baseline levels. If, despite fluid management, mean arterial pressure (MAP) fell by $>10 \mathrm{~mm} \mathrm{Hg}$ from baseline levels, a continuous i.v. infusion of AVP or selepressin was titrated to raise and maintain MAP within $10 \mathrm{~mm} \mathrm{Hg}$ of baseline. Effects of combination treatment of selepressin with the selective $\mathrm{V}_{2} \mathrm{R}$ agonist desmopressin were similarly investigated.

Measurements and Main Results-In septic sheep, MAP fell by $\sim 30 \mathrm{~mm} \mathrm{Hg}$, systemic vascular resistance index (SVRI) decreased by $\sim 50 \%$, and $\sim 7 \mathrm{~L}$ of fluid were retained over $24 \mathrm{~h}$; this fluid accumulation was partially reduced by AVP and almost completely blocked by selepressin; combined infusion of selepressin and desmopressin increased fluid accumulation to levels similar to AVP treatment.

Conclusions-Resuscitation with the selective $\mathrm{V}_{1 \mathrm{a}} \mathrm{R}$ agonist selepressin blocked vascular leak more effectively than the mixed $\mathrm{V}_{1 \mathrm{a}} \mathrm{R} / \mathrm{V}_{2} \mathrm{R}$ agonist AVP because of its lack of agonist activity at the $\mathrm{V}_{2} \mathrm{R}$.

\section{Keywords}

vasopressins; vasopressin $\mathrm{V}_{1 \mathrm{a}}$ receptor; vasopressin $\mathrm{V}_{2}$ receptor; vasoconstrictor agents; sepsis; capillary leak syndrome

\section{Introduction}

Sepsis continues to be a major cause of morbidity and mortality worldwide $(1,2)$. One of the main causes of this high mortality is a hypotension characteristic of the severe sepsis stage that becomes refractory to fluid resuscitation, at which point it is termed septic shock (3-5). This hypotension is secondary to systemic vasodilatation and microvascular fluid leak (vascular/capillary leak syndrome) (6). To counter this hypotension, vasopressors such as catecholamines or vasopressin have been recommended (7). In many cases, blood vessels are refractory to the vasoconstrictive effect of catecholamines as a result of inactivation by nitration and nitrosation of adrenergic receptors and of the catecholamines themselves (8-10). In laboratory investigations, catecholamine administration has even been reported to increase mortality (11).

Clinical studies have documented that a deficiency in the plasma concentration of the vasopressor hormone $\left[\mathrm{Arg}^{8}\right]$ vasopressin (AVP) may contribute to the development of septic shock (12-14) at least partly related to depletion of neurohypophyseal content (15). This led to the hypothesis that AVP administration might be considered as replacement hormone therapy for septic shock (16). Pilot studies involving the use of low-dose AVP i.v. infusion (. 01-.04 U/min) in patients with shock have shown that the "add-back" AVP therapy may reverse hypotension in catecholamine-resistant septic shock (17-20). A recent large-scale multi-center study, the Vasopressin in Septic Shock Trial (VASST), suggested that such "add-back" AVP therapy (.01-.03 U/min) might reduce mortality in less severe septic shock (21). Also, the AVP analog $\left[\mathrm{Orn}^{8}\right]$ vasopressin (OVP) was shown to produce AVP-like 
vasoconstrictor effects in an anesthetized ovine model of peritonitis-induced septic shock (11).

AVP is the endogenous ligand for the known subtypes of the vasopressin receptors, $V_{1 \mathrm{a}}, \mathrm{V}_{1 \mathrm{~b}}$ $\left(\mathrm{V}_{3}\right)$, and $\mathrm{V}_{2}$, and could also act on the oxytocin receptor at high concentrations, with the $\mathrm{V}_{1 \mathrm{a}} \mathrm{R}$ and $\mathrm{V}_{2} \mathrm{R}$ being the principal subtypes mediating the physiological functions of AVP (22-27). While vasoconstriction is mediated by the $\mathrm{V}_{1 \mathrm{a}} \mathrm{R}(28)$ and is beneficial for the treatment of septic shock, some of the $\mathrm{V}_{2} \mathrm{R}$-mediated effects may be adverse, such as selective vasodilation $(29,30)$, prothrombosis $(30)$, antidiuresis (31), and central nervous system (CNS) changes (27). This led us to hypothesize that a selective $\mathrm{V}_{1 \mathrm{a}} \mathrm{R}$ agonist would be superior to AVP in treating severe sepsis/septic shock.

In the present study, we tested the novel selective and short-acting $\mathrm{V}_{1 \mathrm{a}} \mathrm{R}$ agonist selepressin (FE 202158) $(32,33)$ versus AVP as a titrated first-line vasopressor therapy in an established conscious ovine model of Pseudomonas aeruginosa pneumonia-induced severe sepsis $(34,35)^{1}$.

\section{Methods}

Animals

Forty-five female Merino sheep $(34.0 \pm .5 \mathrm{~kg})$ were included in this study approved by the Institutional Animal Care and Use Committee (IACUC) of the University of Texas Medical Branch (UTMB). The guidelines of the National Institutes of Health (NIH) for the care and use of experimental animals were carefully followed. Animals were individually housed in metabolic cages and were studied in the conscious state. The Investigational Intensive Care Unit at UTMB is an Association for Assessment and Accreditation of Laboratory Animal Care International-approved facility (AAALAC).

\section{Surgical Instrumentation and Measured Variables}

Sheep were anesthetized with ketamine and endotracheally intubated. Anesthesia was maintained using isoflurane $1.5-2.5 \%$ in $60 \% \mathrm{O}_{2}$. Under aseptic conditions, the animals were chronically instrumented for hemodynamic monitoring as described previously (34, 35). Briefly, the following catheters were installed: (i) a femoral artery catheter for mean arterial pressure (MAP) measurement, (ii) a left atrial catheter for measurement of left atrial pressure (LAP), (iii) a Swan-Ganz ${ }^{\mathrm{TM}}$ thermodilution catheter positioned via the jugular vein through the introducer for measurement of central venous pressure (CVP), mean pulmonary arterial pressure (MPAP), pulmonary capillary wedge pressure (PCWP), core body temperature, and cardiac output, as well as for administration of resuscitation fluid, and (iv) a femoral vein catheter for compound administration. Pressures and heart rate were measured using pressure transducers (Model PX3X3 and reusable cable model PX1800, Baxter Edwards Critical Care Division, Irvine, CA) connected to a hemodynamic monitor (7830A, Hewlett Packard, Santa Clara, CA), and cardiac output was measured using a specialized computer (COM-1; Baxter Edwards Critical Care Division, Irvine, CA). Cardiac

\footnotetext{
${ }^{1}$ Some of these results have been presented in meeting abstract form(36).
} 
index (CI) and systemic vascular resistance index (SVRI) were calculated using standard equations. Following the surgical procedure, the animals were allowed to recover for five to seven days with free access to food and water. Baseline hemodynamic data and blood samples were collected just prior to the induction of pneumonia and severe sepsis-i.e., just before the experimental procedures began.

\section{Induction of pneumonia and severe sepsis}

Sheep were randomized into 5 study groups (Table 1). They were subjected to ketamine anesthesia $(10 \mathrm{mg} / \mathrm{kg})$ and, after tracheostomy, were placed on mechanical ventilation (Servo Ventilator 900C, Siemens, Elema, Sweden). A Foley catheter was passed through the urethra into the bladder to allow for continuous urine collection for measurement of urine output. Anesthesia was then maintained using 1.5-2.5\% isoflurane in $60 \% \mathrm{O}_{2}$. Induction of pneumonia was performed according to an established protocol $(34,35)$. Briefly, acute lung injury was induced by inhalation of 48 breaths of cooled cotton smoke $\left(<40^{\circ} \mathrm{C}\right)$ using a modified bee smoker through the tracheostomy tube. A suspension of live Pseudomonas aeruginosa $\left(5 \cdot 10^{11}\right.$ colony-forming units in $30 \mathrm{~mL}$ of normal saline) was instilled with a bronchoscope into the right lower and middle lobes as well as the left lower lobe $(10 \mathrm{~mL} /$ lobe) of the lungs to induce pneumonia. The sham animals were insufflated with room air and instilled normal saline.

Anesthesia was then discontinued to allow the animals to regain consciousness for the remainder of the experiment (to avoid any confounding influence of anesthesia) but mechanical ventilation was maintained with a tidal volume of $15 \mathrm{~mL} / \mathrm{kg}$ and a positive endexpiratory pressure of $5 \mathrm{~mm} \mathrm{Hg}$ according to an establish protocol taking into account ovine-specific airway physiology $(37,38)$. The fraction of inspired oxygen $\left(\mathrm{F}_{\mathrm{i}} \mathrm{O}_{2}\right)$ was initially set at 1.0 and adjusted if needed to maintain arterial partial pressure of oxygen $\left(\mathrm{P}_{\mathrm{a}} \mathrm{O}_{2}\right)$ above $90 \mathrm{~mm} \mathrm{Hg}$. Respiration rate was initially set at 30 breaths $/ \mathrm{min}$ and adjusted if needed to maintain the arterial partial pressure of carbon dioxide $\left(\mathrm{P}_{\mathrm{a}} \mathrm{CO}_{2}\right) \sim 10 \%$ below baseline values to avoid the influence of sedation on cardiovascular function (34).

\section{Resuscitation Treatment}

Resuscitation treatment was designed to approximate the management of sepsis patients in an intensive care unit, using a combination of fluid resuscitation followed by vasopressor agent administration. Starting immediately after induction of pneumonia, all animals were fluid resuscitated with lactated Ringer's solution by i.v. infusion through the proximal injection port of the Swan-Ganz ${ }^{\mathrm{TM}}$ catheter with an initial baseline infusion rate of 2 $\mathrm{mL} \cdot \mathrm{kg}^{-1} \cdot \mathrm{h}^{-1}$. Hematocrit was monitored hourly (hemoconcentration was used as a marker of sepsis-associated vascular leak) and fluid infusion rate was titrated accordingly (2 $\mathrm{mL} \cdot \mathrm{kg}^{-1} \cdot \mathrm{h}^{-1}$ per \% point change) to maintain hematocrit at baseline levels $( \pm 3 \%)$. During the 24-h study period, all animals had free access to food, but not to water, in order to precisely control fluid balance. Since sheep do not sweat and ventilation was performed with gas saturated with water vapor, insensible fluid losses were negligible and fluid balance was calculated by subtracting urine output from fluid intake. Although hematocrit is not used in clinical practice to titrate fluid resuscitation, using this approach here allowed for indirect quantification of vascular leak syndrome through measurement of fluid intake requirements 
and the associated fluid balance. Monitoring of plasma total protein concentration using a refractometer (National Instruments, Baltimore, MD) and plasma oncotic pressure using a colloid osmometer (Model 4420, Wescor, Logan, UT) was also used to indirectly quantify vascular leak.

Mean arterial pressure (MAP) was monitored hourly after induction of pneumonia until it decreased by more than $10 \mathrm{~mm} \mathrm{Hg}$ below baseline levels despite fluid resuscitation-in this conscious sheep model, this magnitude of hypotension in the presence of aggressive fluid resuscitation qualifies as advanced severe sepsis. Infusion of vasopressor compounds (AVP, selepressin, or selepressin+dDAVP) through the femoral vein catheter was then initiated. The initial infusion rates for the mixed $\mathrm{V}_{1 \mathrm{a}} \mathrm{R} / \mathrm{V}_{2} \mathrm{R}$ agonist $\mathrm{AVP}$ and the selective $\mathrm{V}_{1 \mathrm{a}} \mathrm{R}$ agonist selepressin were $23 \mathrm{pmol} / \mathrm{min}\left(\sim .7 \mathrm{pmol} \bullet \mathrm{kg}^{-1} \bullet \mathrm{min}^{-1}\right)$ and $239 \mathrm{pmol} / \mathrm{min}(\sim 7$ $\left.\mathrm{pmol} \bullet \mathrm{kg}^{-1} \bullet \mathrm{min}^{-1}\right)$, respectively, both corresponding to a volume rate of $10 \mathrm{mcL} / \mathrm{min}$. The initial infusion rate for AVP was based on the infusion rate of OVP shown to produce AVPlike vasopressor effect in an anesthetized ovine model of peritonitis-induced septic shock (11) and the initial infusion rate for selepressin was set higher to compensate for lower potency of selepressin at the $\mathrm{V}_{1 \mathrm{a}} \mathrm{R}$ compared to AVP (32) assuming similar systemic clearance values for the two compounds. MAP was monitored at least every 30 minutes and the infusion rate was titrated accordingly up or down by steps of $10 \mathrm{mcL} / \mathrm{min}$ to maintain MAP at baseline levels $( \pm 10 \mathrm{~mm} \mathrm{Hg}$ ) for the remainder of the 24-h study period.

To assess the consequence of the lack of activity of selepressin at the $\mathrm{V}_{2} \mathrm{R}$ in the differentiated effects of selepressin versus AVP, the selective $V_{2} R$ agonist desmopressin (dDAVP) was co-administered with selepressin to some animals (Sepsis+selepressin +dDAVP group). Specifically, dDAVP was administered as constant i.v. infusion (1.13 $\mathrm{pmol} \bullet \mathrm{kg}^{-1} \cdot \mathrm{min}^{-1}, \sim 30 \mathrm{mcL} / \mathrm{min}$ ), beginning 1 hour after pneumonia induction and maintained for the remainder of the 24-h study period in addition to the titrated infusion of selepressin that was started and continued as described above. This infusion rate of dDAVP was shown to be antidiuretic in hydrated sheep (39) and was kept constant to magnify any potential effect of $\mathrm{V}_{2} \mathrm{R}$ activation. The infusion was started 1 hour after pneumonia induction to allow for plasma dDAVP concentration to closely approach steady-state by the time MAP levels would decrease sufficiently for selepressin infusion to be started—dDAVP infusion requires 2 hours to reach steady-state plasma concentration in sheep compared to 30 minutes for AVP $(40,41)$.

After completion of the 24-h experiment, the animals were anesthetized with ketamine (15 $\mathrm{mg} / \mathrm{kg}$ ) and sacrificed by intravenous injection of $60 \mathrm{~mL}$ of a saturated solution of potassium chloride. To confirm the establishment of pneumonia, histological assessment of lung tissue in the Sepsis and Sham groups was performed as previously described (42). A pathologist without knowledge of the injury or treatment protocol evaluated four sections of tissue from each animal and assigned semi-quantitative scores between 0 (normal) and 4 (severe) for the extent of alveolar edema, the level of alveolar neutrophils, and the level of alveolar bacteria. For each of these three variables, the final score per animal was calculated as the mean score from the four sections. 
Drugs

All chemicals, unless otherwise stated, were of at least U.S.P. grade and used as received from commercial suppliers. Selepressin $\left(\left[\mathrm{Phe}^{2}, \mathrm{Ile}^{3}, \mathrm{Hgn}^{4}, \mathrm{Orn}(\mathrm{iPr})^{8}\right]\right.$ vasopressin, where Hgn is homoglutamine and $\mathrm{Pr}$ is isopropyl) $(32,33), \mathrm{AVP}\left(\left[\mathrm{Arg}^{8}\right]\right.$ vasopressin), and dDAVP (desmopressin, desamino-[D-Arg $\left.{ }^{8}\right]$ vasopressin) were synthesized as acetate salts at Ferring Research Institute, Inc. (San Diego, CA).

\section{Data Analysis}

Results are expressed as mean \pm SEM unless otherwise stated. Variables were analyzed using a mixed-effect model with the statistical software SAS (SAS Institute Inc., Cary, NC) with treatment (i.e., study group), time, and the interaction between treatment and time as factors. No variables severely deviated from normal distribution as tested by residuals distribution assessment using histogram and Q-Q plot methods, except for cumulative fluid intake, cumulative urine output, and cumulative fluid balance which required logarithmic transformation before analysis. Using the Akaike information criterion (AIC), the first-order heterogeneous autoregressive covariance structure was found to best describe the correlation among the repeated measures. When the interaction term between treatment and time was significant, the treatment effect was studied under each single time point and the time effect was studied for each treatment. Holm-Bonferroni post-hoc test was used for multiple comparisons. For the histological variables, comparisons between the Sepsis and Sham groups were made using the Ranked Sum Test while, for the variables analyzed at a single time point (body temperature, heart rate, and circulating white blood cells), comparisons between the Sepsis and Sham groups were made using the bilateral Student's t test—-both analyses were performed with the statistical software SigmaPlot (Systat, Chicago, IL). The overall survival was analyzed using Kaplan-Meier plots with the statistical software $\mathrm{R}$ (http://www.r-project.org/, The R Foundation for Statistical Computing, Vienna, Austria), incorporating both the mortality data and the time of animal death. The logrank test was used for testing the equality of hazard rates among groups. For all statistical analyses, a $P<$. 05 was regarded as statistically significant.

\section{Results}

\section{Cardiorespiratory Response}

The induction of pneumonia resulted in decreased mean $\mathrm{P}_{\mathrm{a}} \mathrm{O}_{2} / \mathrm{F}_{\mathrm{i}} \mathrm{O}_{2}$ ratios to less than 200 , a criterion for acute respiratory distress syndrome (ARDS) (Table 2). Histological evidence of pneumonia (semi-quantitative scores) was demonstrated in the Sepsis group by the presence of bacteria in the alveoli $(1.4 \pm .4$ vs. 0 in the Sham group, $\mathrm{P}<.05)$ together with an increase in alveolar edema $(2.5 \pm .4$ vs. $.4 \pm .2$ in the Sham group, $\mathrm{P}<.05)$ and alveolar neutrophils $(2.4 \pm .4$ vs. 0 in the Sham group, $\mathrm{P}<.05)$ (Figure 1). In these animals, body temperature ( $40.1 \pm .2$ vs. $39.4 \pm .2^{\circ} \mathrm{C}$ in the Sham group, $\mathrm{P}<.05$ [normal sheep body temperature is $\left.\left.\sim 39.6^{\circ} \mathrm{C}\right]\right)$ and heart rate $(111 \pm 4$ vs. $93 \pm 5 \mathrm{BPM}$ in the Sham group, $\mathrm{P}<.05)$ were increased by 3 hours after lung injury and circulating white blood cells were severely decreased by 12 hours after injury (1766 \pm 240 vs. $7483 \pm 1303$ cells/mcL in the Sham group, $\mathrm{P}<.05)$. These clinical signs of sepsis were associated with a significant decrease in MAP of $\sim 30 \mathrm{~mm} \mathrm{Hg}$ from baseline values and in SVRI of $\sim 50 \%$ of baseline values by the 
end of the 24-h study (Figure 2). Taken together, these results indicate that lung injury led to the development of pneumonia and associated severe sepsis. The sizable decrease in MAP occurred despite aggressive fluid resuscitation (Figure 3) and a significant increase in cardiac filling pressures (CVP, LAP) and in cardiac index (Table 2).

Titrated vasopressor infusion (either the mixed $V_{1 a} R / V_{2} R$ agonist AVP or the selective $\mathrm{V}_{1 \mathrm{a}} \mathrm{R}$ agonist selepressin) maintained average MAP values above those in the Sepsis group (Figure 2) and almost always within the target range of $10 \mathrm{~mm} \mathrm{Hg}$ from baseline valueswhile statistical significance was not reached in the Sepsis+AVP group vs. the Sepsis group, average MAP values at the 12 and 24-h time points were not significantly lower than baseline levels for the Sepsis+AVP group. Despite the fact that the average infusion rate increased over time for selepressin more than for AVP (Table 2), almost all sheep in both groups had their MAP within target range by the 24-h time point ( 8 out of 9 in the Sepsis +selepressin group, 6 out of 7 in the Sepsis+AVP group) suggesting that success of vasopressor support was comparable between the AVP and selepressin treatment groups from the MAP target range perspective.

SVRI was higher in the Sepsis+AVP and Sepsis+selepressin groups than in the Sepsis group (Figure 2) but this increase reached statistical significance only for the Sepsis+selepressin group. Cardiac index remained stable relative to baseline in the Sepsis+AVP and Sepsis + selepressin groups (Table 2).

\section{Surrogate Markers of Vascular Leak Syndrome}

Titrated fluid resuscitation succeeded at maintaining mean hematocrit values near baseline values $( \pm 3 \%$ ) in all groups (Table 2 ). The required cumulative fluid intake was significantly lower in the Sepsis+selepressin group than in the Sepsis group (Figure 3). In contrast, the slightly lower cumulative fluid intake in the Sepsis+AVP group compared to the Sepsis group at 12 and 18 hours did not reach statistical significance and, by the 24-h time point, the Sepsis+AVP group had required nearly the same amount of fluid as the Sepsis group. Cumulative urine output increased over time (i.e., significant effect of time) although there was no significant effect related to study groups or to the interaction between study group and time (Figure 3). This resulted in a cumulative fluid balance that significantly increased over time in the Sepsis group reaching an average of up to $\sim 200 \mathrm{~mL} / \mathrm{kg}(\sim 20 \%$ of the sheep initial average body weight) (Figure 3 ). Cumulative fluid balance also significantly increased over time in the Sepsis+AVP group, although on average in a less fulminant way (e.g., it was significantly lower than in the Sepsis group at $18 \mathrm{~h}$ ), whereas there was virtually no fluid accumulation in the Sepsis+selepressin group.

Plasma total protein concentration significantly decreased in the Sepsis group over time and relative to the Sham group (Figure 4). This decrease was significantly attenuated in the Sepsis+selepressin and Sepsis+AVP groups. Similar changes occurred for plasma oncotic pressure, except that the decrease attenuation in the Sepsis+AVP group versus the Sepsis group was significant only at $12 \mathrm{~h}$. 


\section{Survival}

Death started occurring 12 hours after lung injury, and four of the fourteen (29\%) sheep in the Sepsis group expired by the end of the 24-h study period (Figure 5). There was one fatality (1/10) in the Sepsis+AVP and no fatality (0/9) in the Sepsis+selepressin group. The survival analysis using the logrank test produced a $P$-value of .17 , indicating no sufficient statistical evidence to conclude that the risk of death was significantly different between treatment groups but this study was not powered to determine the statistical differences in survival.

\section{Effect of $V_{2} R$ Agonism on Surrogate Markers of Vascular Leak Syndrome}

The selective $\mathrm{V}_{2} \mathrm{R}$ agonist dDAVP was co-administered with selepressin (Sepsis +selepressin+dDAVP group) to test the hypothesis that the difference observed between $A V P$ and selepressin relative to vascular leak syndrome surrogate markers is due to the $V_{2} R$ agonist activity of AVP. While MAP could be maintained in the Sepsis+selepressin +dDAVP group $(89.3 \pm 8.2 \mathrm{~mm} \mathrm{Hg}$ at $24 \mathrm{~h}$ vs. $102.8 \pm 2.7 \mathrm{~mm} \mathrm{Hg}$ at baseline; 5 out of 6 sheep had their MAP within $10 \mathrm{~mm} \mathrm{Hg}$ from baseline value at $24 \mathrm{~h}$ ) with success comparable to the Sepsis+selepressin group $(90.6 \pm 3.8 \mathrm{~mm} \mathrm{Hg}$ at $24 \mathrm{~h}$ vs. $94.9 \pm 1.9 \mathrm{~mm}$ $\mathrm{Hg}$ at baseline; 8 out of 9 had their MAP within $10 \mathrm{~mm} \mathrm{Hg}$ from baseline value at $24 \mathrm{~h}$ ), the addition of dDAVP to the selepressin treatment increased cumulative fluid intake and balance (Figure 6) and decreased plasma total protein concentration and oncotic pressure (Figure 7) to the levels observed in the Sepsis+AVP group.

\section{Discussion}

The results reported here suggest that a selective $\mathrm{V}_{1 \mathrm{a}} \mathrm{R}$ agonist such as selepressin could be used as a titrated first-line vasopressor in the treatment of severe sepsis and may be advantageous over the mixed $\mathrm{V}_{1 \mathrm{a}} \mathrm{R} / \mathrm{V}_{2} \mathrm{R}$ agonist $\mathrm{AVP}$. The most remarkable and unexpected finding in this study was the ability of selepressin to almost completely block vascular leak. Indeed, there were signs of pronounced vascular leak syndrome in the Sepsis group typical of the phenomenon observed in septic humans (6): a marked increase in cumulative fluid intake and balance together with a pronounced decrease in plasma total protein concentration and oncotic pressure-since hematocrit was maintained at baseline level through titrated fluid resuscitation in order to keep plasma volume constant, the decrease is unlikely to be dilutional. In the Sepsis+selepressin group, cumulative fluid intake was significantly reduced and cumulative fluid balance was near zero. This reduction in fluid accumulation by selepressin was associated with a significant blunting of the fall in plasma total protein concentration and oncotic pressure. Interestingly, AVP was not as effective as selepressin at blocking vascular leak despite the fact that both compounds were titrated aggressively to maintain MAP in the absence of antibiotic therapy-severe sepsis in this animal model is more rapidly lethal than severe sepsis in humans (43). The difference in efficacy at blocking vascular leak between selepressin and AVP appears to be related to the pronounced agonist activity of $\mathrm{AVP}$ at the $\mathrm{V}_{2} \mathrm{R}(32,33)$. Indeed, addition of the selective $\mathrm{V}_{2} \mathrm{R}$ agonist dDAVP to the selepressin treatment decreased the amplitude of the antivascular leak effect down to the amplitude observed with the AVP treatment. 
The present findings are supported by recent results from another study with the selective $\mathrm{V}_{1 \mathrm{a}} \mathrm{R}$ agonist $\left[\mathrm{Phe}^{2}, \mathrm{Ile}^{3}, \mathrm{Orn}^{8}\right]$ vasopressin (POV) in an anesthetized ovine model of cecal ligation and puncture-induced septic shock (44). However, unlike the present study, in which AVP and selepressin were used as first-line therapy, AVP and POV were delivered only after administration of norepinephrine had exceeded $1 \mu \mathrm{g} / \mathrm{kg} / \mathrm{min}$ (i.e., as second-line vasopressor therapy similar to clinical uses of AVP). In addition, the investigators used a fixed continuous i.v. infusion dose of POV (mimicking the design of VASST (21)) while selepressin in the present study was used as first-line vasopressor therapy and titrated to maintain MAP. Although, the magnitude of the observed changes in MAP and net fluid balance with POV treatment were physiologically minimal compared to the magnitudes reported here with selepressin (likely because of the different dosing regimen), the beneficial effect of selective $\mathrm{V}_{1 \mathrm{a}} \mathrm{R}$ agonism was still present.

More recently, we have studied the effects of POV versus AVP in our conscious ovine model of methicillin-resistant Staphylococcus aureus (MRSA) pneumonia-induced severe sepsis using the same fluid resuscitation and vasopressor titration protocol as in the present study (45). This model is characterized by a more severe vascular leak syndrome than the $P$. aeruginosa pneumonia-induced severe sepsis model studied here (46). Consistent with the observations that we reporting here, we showed that POV was superior to AVP at stabilizing MAP and SVRI and at reducing vascular leak, as shown by a reduction in fluid requirements, cumulative fluid balance, and thoracic cavity and abdominal cavity fluid accumulation, as well as by an attenuation of the decrease in plasma total protein concentration and plasma oncotic pressure.

Thus, the consistency in the $\mathrm{V}_{1 \mathrm{a}} \mathrm{R}$ mediated anti-leakage effect in three different sheep models of severe sepsis/septic shock strengthens the relevance of the findings herein and the likelihood that it will translate into similar effects in humans.

As mentioned, low-dose continuous AVP i.v. infusion has been used with some success in numerous septic shock clinical trials (17-20). However, in the largest and most recent trial, VASST (21), low-dose continuous infusion of AVP was not successful at reducing mortality in the most severe cases (defined by resistance to catecholamines). One may hypothesize that low-dose continuous infusion of a $\mathrm{V}_{1 \mathrm{a}} \mathrm{R}$ agonist as second-line therapy is not ideal; use as first-line therapy with titration based on the patient's requirements to maintain MAP may be more effective. Furthermore, it was recently shown in a large European study (SOAP) that a positive fluid balance was among the strongest prognostic factors for intensive care unit (ICU) mortality in septic patients $(47,48)$, and positive fluid balance was associated with increasing mortality in patients who had septic shock in VASST (49).

In sum, this study in a clinically relevant conscious ovine model of severe sepsis suggests that the selective $\mathrm{V}_{1 \mathrm{a}} \mathrm{R}$ agonist selepressin could be used as a titrated first-line vasopressor agent. With this treatment modality, selepressin was more efficacious than the mixed $\mathrm{V}_{1 \mathrm{a}} \mathrm{R} / \mathrm{V}_{2} \mathrm{R}$ agonist $\mathrm{AVP}$ at blocking vascular leak. 


\section{Acknowledgments}

The authors would like to acknowledge the team of the Investigational ICU at UTMB for outstanding technical support and, from Ferring Research Institute, the expert assistance of Robert Galyean for the chemical synthesis of AVP, dDAVP, and selepressin, Dr. Tracey Fisher, Dr. Chia-Ping Chang, and Denise Riedl for scientific auditing, as well as Karina Mena for bibliographic work. The authors would also like to acknowledge Dr. Anne Louise Kjølbye from Ferring Pharmaceuticals for critical review of the manuscript and Dr. Barbara A. Bailey from San Diego State University for statistical review of the manuscript. Drs. Marc O. Maybauer, Dirk M. Maybauer, Enkhbaatar, Traber, Hawkins, Cox, and Traber are/were employees of the University of Texas Medical Branch at Galveston, which was contracted by the Ferring Research Institute to conduct the study reported here. Drs. Lin and Fan are employees of Forestat Consulting Group, which was contracted by the Ferring Research Institute to conduct the statistical analysis of the study reported here. Drs. Laporte, Wiśniewski, Schteingart, and Rivière and Ms. Wiśniewska are/ were employees of the Ferring Research Institute. Dr. Lin consulted for Ferring Research Institute. Drs. Landry and Traber were consultants for the Ferring Research Institute. Drs. Laporte, Wiśniewski, Schteingart, and Rivière have patents granted and pending on FE 202158. Drs. Enkhbaatar and Traber received funding from the National Institutes of Health (GM097480) and Shriners of North America (SHC84050). In Memoriam of Professor Daniel L. Traber.

Financial Support: This work was financially supported by Ferring Research Institute, Inc., San Diego, CA, USA; by the National Institutes of Health (GM097480); and by Shriners of North America (SHC84050).

\section{References}

1. Angus DC, Pereira CA, Silva E. Epidemiology of severe sepsis around the world. Endocr Metab Immune Disord Drug Targets. 2006; 6:207-212. [PubMed: 16787296]

2. Yende S, Angus DC. Long-term outcomes from sepsis. Curr Infect Dis Rep. 2007; 9:382-386. [PubMed: 17880848]

3. Bone RC, Balk RA, Cerra FB, et al. Definitions for sepsis and organ failure and guidelines for the use of innovative therapies in sepsis. The ACCP/SCCM Consensus Conference Committee. American College of Chest Physicians/Society of Critical Care Medicine. Chest. 1992; 101:16441655. [PubMed: 1303622]

4. Rivers E. The outcome of patients presenting to the emergency department with severe sepsis or septic shock. Crit Care. 2006; 10:154. [PubMed: 16887012]

5. Huang DT, Clermont G, Dremsizov TT, et al. Implementation of early goal-directed therapy for severe sepsis and septic shock: A decision analysis. Crit Care Med. 2007; 35:2090-2100. [PubMed: 17855823]

6. Jacobson JR, Garcia JG. Novel therapies for microvascular permeability in sepsis. Curr Drug Targets. 2007; 8:509-514. [PubMed: 17430121]

7. Dellinger RP, Levy MM, Carlet JM, et al. Surviving Sepsis Campaign: international guidelines for management of severe sepsis and septic shock: 2008. Crit Care Med. 2008; 36:296-327. [PubMed: 18158437]

8. Daveu C, Servy C, Dendane M, et al. Oxidation and nitration of catecholamines by nitrogen oxides derived from nitric oxide. Nitric Oxide. 1997; 1:234-243. [PubMed: 9704585]

9. Takakura K, Taniguchi T, Muramatsu I, et al. Modification of alpha1 -adrenoceptors by peroxynitrite as a possible mechanism of systemic hypotension in sepsis. Crit Care Med. 2002; 30:894-899. [PubMed: 11940765]

10. Takakura K, Xiaohong W, Takeuchi K, et al. Deactivation of norepinephrine by peroxynitrite as a new pathogenesis in the hypotension of septic shock. Anesthesiology. 2003; 98:928-934. [PubMed: 12657855]

11. Sun Q, Dimopoulos G, Nguyen DN, et al. Low-dose vasopressin in the treatment of septic shock in sheep. Am J Resp Crit Care Med. 2003; 168:481-486. [PubMed: 12791578]

12. Landry DW, Levin HR, Gallant EM, et al. Vasopressin deficiency contributes to the vasodilation of septic shock. Circulation. 1997; 95:1122-1125. [PubMed: 9054839]

13. Sharshar T, Blanchard A, Paillard M, et al. Circulating vasopressin levels in septic shock. Crit Care Med. 2003; 31:1752-1758. [PubMed: 12794416]

14. Jochberger S, Dorler J, Luckner G, et al. The vasopressin and copeptin response to infection, severe sepsis, and septic shock. Crit Care Med. 2009; 37:476-482. [PubMed: 19114902] 
15. Sharshar T, Carlier R, Blanchard A, et al. Depletion of neurohypophyseal content of vasopressin in septic shock. Crit Care Med. 2002; 30:497-500. [PubMed: 11990905]

16. Oliver JA, Landry DW. Endogenous and exogenous vasopressin in shock. Curr Opin Crit Care. 2007; 13:376-382. [PubMed: 17599006]

17. Farand P, Hamel M, Lauzier F, et al. Review article: organ perfusion/permeability-related effects of norepinephrine and vasopressin in sepsis. Can J Anaesth. 2006; 53:934-946. [PubMed: 16960272]

18. Barrett LK. Vasopressin: Mechanisms of action on the vasculature in health and in septic shock. Crit Care Med. 2007; 35:33-40. [PubMed: 17133186]

19. Russell JA. Vasopressin in septic shock. Crit Care Med. 2007; 35:S609-S615. [PubMed: 17713417]

20. Russell JA. Vasopressin in vasodilatory and septic shock. Curr Opin Crit Care. 2007; 13:383-391. [PubMed: 17599007]

21. Russell JA, Walley KR, Singer J, et al. Vasopressin versus norepinephrine infusion in patients with septic shock. N Engl J Med. 2008; 358:877-887. [PubMed: 18305265]

22. Howl J, Wheatley M. Molecular pharmacology of V1a vasopressin receptors. Gen Pharmacol. 1995; 26:1143-1152. [PubMed: 7590102]

23. Barberis C, Mouillac B, Durroux T. Structural bases of vasopressin/oxytocin receptor function. J Endocrinol. 1998; 156:223-229. [PubMed: 9518866]

24. Jard S. Vasopressin receptors. A historical survey. Adv Exp Med Biol. 1998; 449:1-13. [PubMed: 10026781]

25. Oshikawa S, Tanoue A, Koshimizu TA, et al. Vasopressin stimulates insulin release from islet cells through V1b receptors: a combined pharmacological/knockout approach. Mol Pharmacol. 2004; 65:623-629. [PubMed: 14978240]

26. Ring RH. The central vasopressinergic system: examining the opportunities for psychiatric drug development. Curr Pharm Des. 2005; 11:205-225. [PubMed: 15638758]

27. Caldwell HK. Oxytocin and vasopressin: Genetics and behavioral implications. Neurochem Mol Neurobiol. 2006:1-35.

28. Maybauer MO, Maybauer DM, Enkhbaatar P, et al. Physiology of the vasopressin receptors. Best Pract Res Clin Anaesthesiol. 2008; 22:253-263. [PubMed: 18683472]

29. Aki Y, Tamaki T, Kiyomoto H, et al. Nitric oxide may participate in V2 vasopressin-receptormediated renal vasodilation. J Cardiovasc Pharmacol. 1994; 23:331-336. [PubMed: 7511766]

30. Kaufmann JE, Vischer UM. Cellular mechanisms of the hemostatic effects of desmopressin (DDAVP). J Thromb Haemost. 2003; 1:682-689. [PubMed: 12871401]

31. Knepper MA. Molecular physiology of urinary concentrating mechanism: regulation of aquaporin water channels by vasopressin. Am J Physiol. 1997; 272:F3-12. [PubMed: 9039043]

32. Laporte R, Kohan A, Heitzmann J, et al. Pharmacological Characterization of FE 202158, a Novel, Potent, Selective, and Short-Acting Peptidic Vasopressin V1a Receptor Full Agonist for the Treatment of Vasodilatory Hypotension. J Pharmacol Exp Ther. 2011; 337:786-796. [PubMed: 21411496]

33. Wisniewski K, Galyean R, Taki H, et al. Synthesis and in vitro pharmacological profile of potent and selective peptidic V1a receptor agonists. Adv Exp Med Biol. 2009; 611:507-508. [PubMed: 19400287]

34. Murakami K, Bjertnaes LJ, Schmalstieg FC, et al. A novel animal model of sepsis after acute lung injury in sheep. Crit Care Med. 2002; 30:2083-2090. [PubMed: 12352045]

35. Maybauer DM, Maybauer MO, Traber LD, et al. Effects of severe smoke inhalation injury and septic shock on global hemodynamics and microvascular blood flow in sheep. Shock. 2006; 26:489-495. [PubMed: 17047520]

36. Traber DL. Selective V1a receptor agonists in experimental septic shock. Crit Care. 2007; 11:S23.

37. Lange M, Traber DL, Enkhbaatar P. The authors reply. Crit Care Med. 2011; 40:356-357.

38. Maybauer DM, Talke PO, Westphal M, et al. Positive end-expiratory pressure ventilation increases extravascular lung water due to a decrease in lung lymph flow. Anaesth Intensive Care. 2006; 34:329-333. [PubMed: 16802485] 
39. Yesberg NE, Henderson M, Budtz-Olsen OE. The effects of two analogues of arginine-vasopressin (ornithine-vasopressin and desamino-D-argininevasopressin) on kidney function in sheep. Q J Exp Physiol Cogn Med Sci. 1978; 63:179-188. [PubMed: 247535]

40. Stegner H, Artman HG, Leake RD, et al. DDAVP (1-desamino-8-D-arginine vasopressin) clearance rate. Acta Endocrinol (Copenh). 1984; 107:204-206. [PubMed: 6495988]

41. Stegner H, Leake RD, Palmer SM, et al. Arginine vasopressin metabolic clearance and production rates in fetal sheep, pregnant ewes, and lambs. Dev Pharmacol Ther. 1984; 7:87-93. [PubMed: 6705658]

42. Enkhbaatar P, Murakami K, Traber LD, et al. The inhibition of inducible nitric oxide synthase in ovine sepsis model. Shock. 2006; 25:522-527. [PubMed: 16680018]

43. Nakano Y, Maybauer MO, Maybauer DM, et al. A novel antibiotic based long-term model of ovine smoke inhalation injury and septic shock. Burns. 2010; 36:1050-1058. [PubMed: 20395054]

44. Rehberg S, Ertmer C, Vincent JL, et al. Role of selective V1a receptor agonism in ovine septic shock. Crit Care Med. 2011; 39:119-125. [PubMed: 20890184]

45. Rehberg S, Yamamoto Y, Sousse LE, et al. Selective V1a agonism attenuates vascular dysfunction and fluid accumulation in ovine severe sepsis. Am J Physiol. 2012; 303:H1245-H1254.

46. Enkhbaatar P, Joncam C, Traber L, et al. Novel ovine model of methicillin-resistant Staphylococcus aureus-induced pneumonia and sepsis. Shock. 2008; 29:642-649. [PubMed: 17885644]

47. Vincent JL. Sepsis in European intensive care units: Results of the SOAP study. Crit Care Med. 2006; 34:344-353. [PubMed: 16424713]

48. Payen D, de Pont AC, Sakr Y, et al. A positive fluid balance is associated with a worse outcome in patients with acute renal failure. Crit Care. 2008; 12:R74. [PubMed: 18533029]

49. Boyd JH, Forbes J, Nakada TA, et al. Fluid resuscitation in septic shock: A positive fluid balance and elevated central venous pressure are associated with increased mortality. Crit Care Med. 2010; 39:259-265. [PubMed: 20975548] 


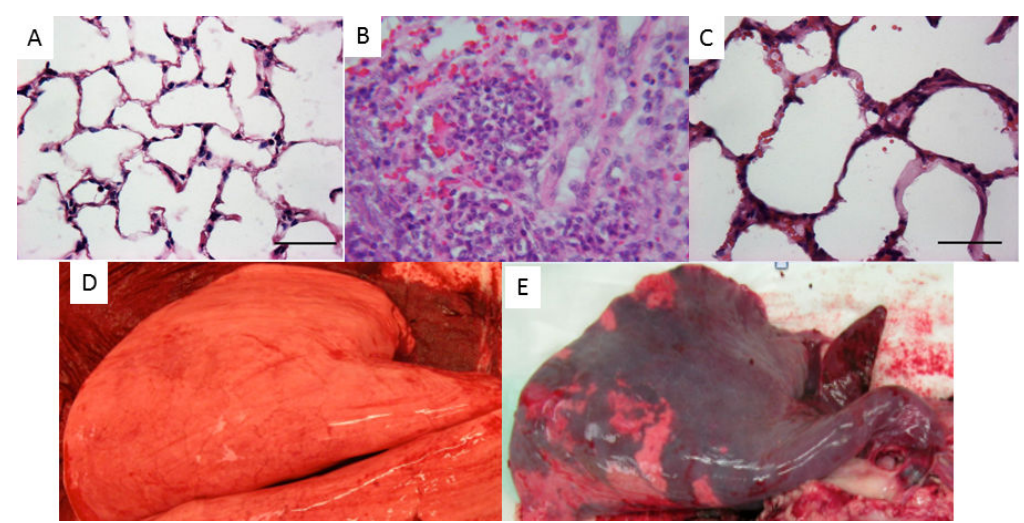

Figure 1.

Upper panel: Micrographs (H\&E staining) of the lung tissues of sheep exposed to sham injury (A), smoke inhalation (B), and smoke inhalation plus airway instillation of Pseudomonas aeruginosa (P. aeruginosa) (C). The lung tissues were taken at 24 hours after the injury. Magnification: 40X. Marked accumulation of neutrophils in alveoli along with severe interstitial edema and congestion could be seen in the lung tissue following combined injury versus moderate septal thickness and accumulation of inflammatory cells in smoke only sheep. Lower panel: Macroscopic pictures of sham-injured (D) and smoke $+P$. aeruginosa-injured (E) lungs. 


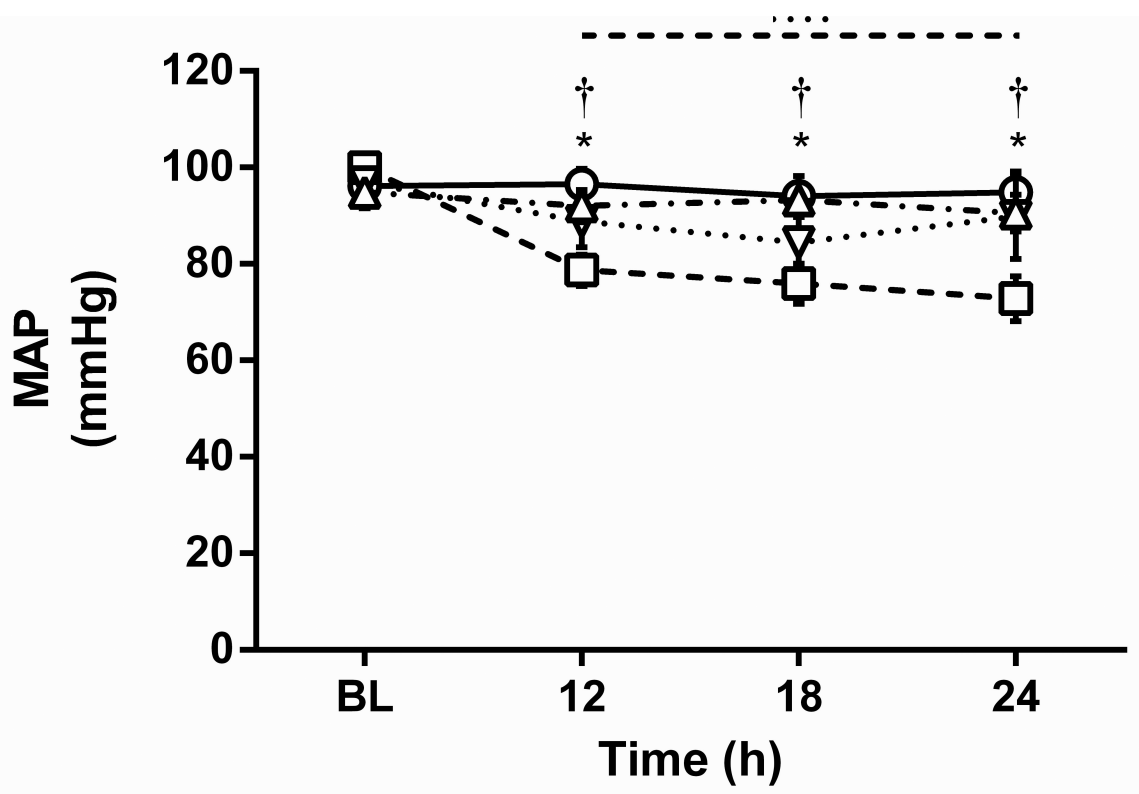

-O- Sham

$\square$. Sepsis

- $\boldsymbol{\nabla}$. Sepsis + AVP

$-\Delta-$ Sepsis + selepressin

Time (h)

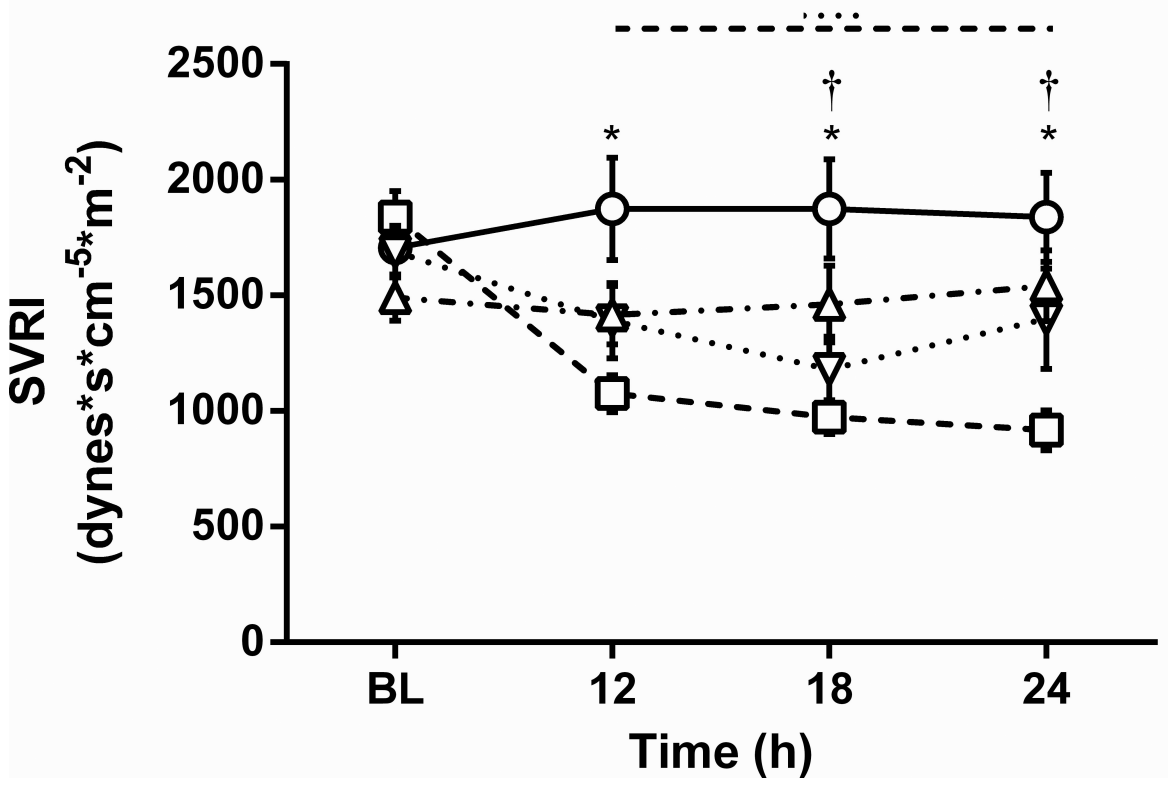

Figure 2.

Effect of AVP and selepressin on mean arterial pressure (MAP) and systemic vascular resistance index (SVRI). Mean \pm SEM are shown. BL: Baseline. Sham $n=6$, Sepsis $n=$ 10-14, Sepsis+AVP $n=7-10$, Sepsis+selepressin $n=9$. Significant change from $B L(P<$. $05)$ is indicated by the lines above the graph shape coded according to legend for study groups. *: $\mathrm{P}<.05$ for Sham vs. Sepsis; $\uparrow: \mathrm{P}<.05$ for Sepsis+selepressin vs. Sepsis. 

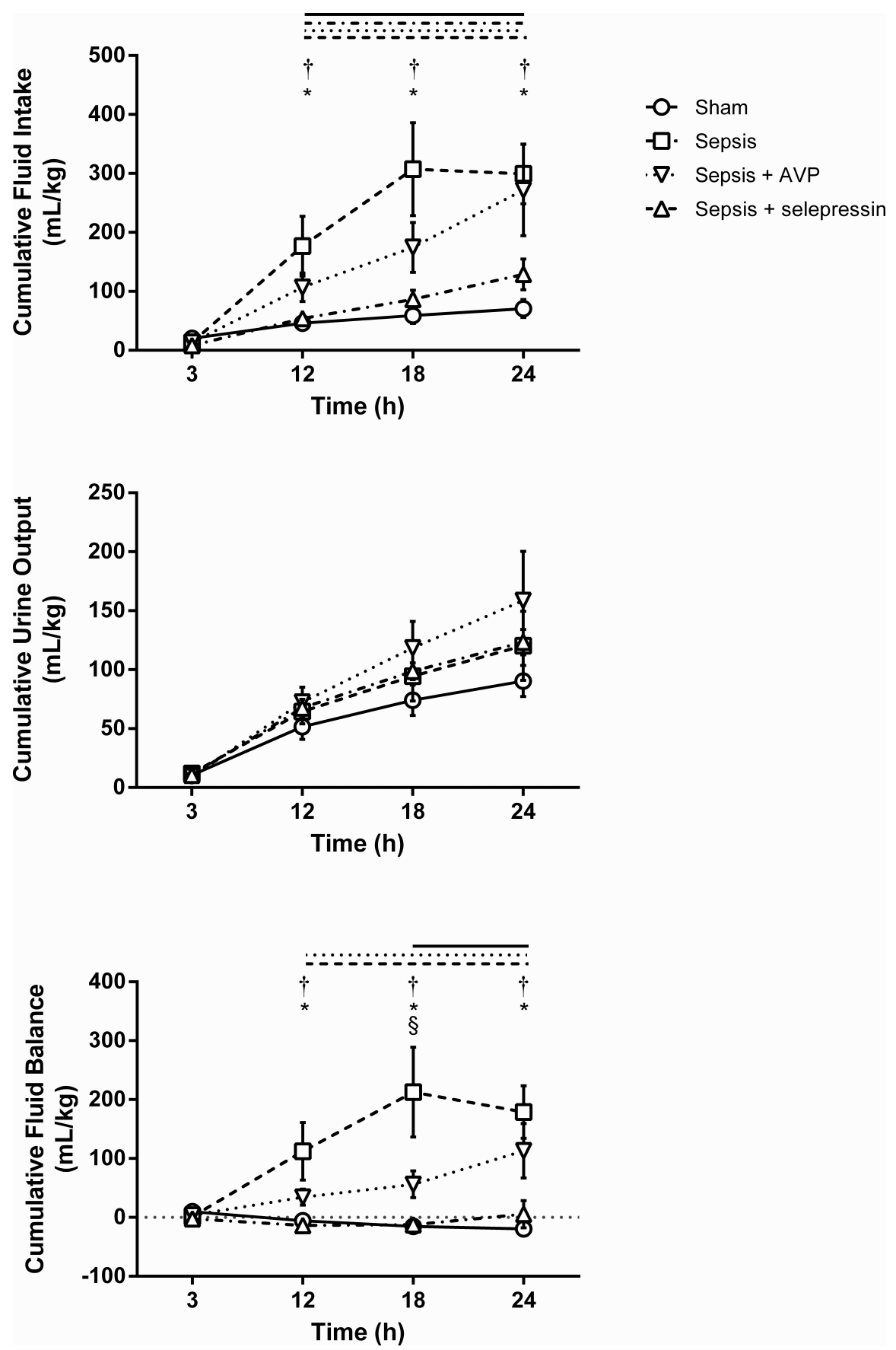

Figure 3.

Effect of AVP and selepressin on cumulative fluid intake, cumulative urine output, and cumulative fluid balance. Mean \pm SEM are shown. Sham $n=6$, Sepsis $n=9-14$, Sepsis +AVP $n=7-10$, Sepsis+selepressin $n=9$. Significant change from the 3 -h time point $(\mathrm{P}<$. $05)$ is indicated by the lines above the graph shape coded according to legend for study groups. *: P < .05 for Sham vs. Sepsis; $\dagger$ : $\mathrm{P}<.01$ for Sepsis+selepressin vs. Sepsis; $\S: \mathrm{P}<$. 05 for Sepsis+selepressin vs. Sepsis+AVP. For cumulative urine output, the time effect was 
significant $(\mathrm{P}<.05)$ but the interaction between study groups and time was not $(\mathrm{P}=.99)$ preventing the analysis of the time effect per study group. 


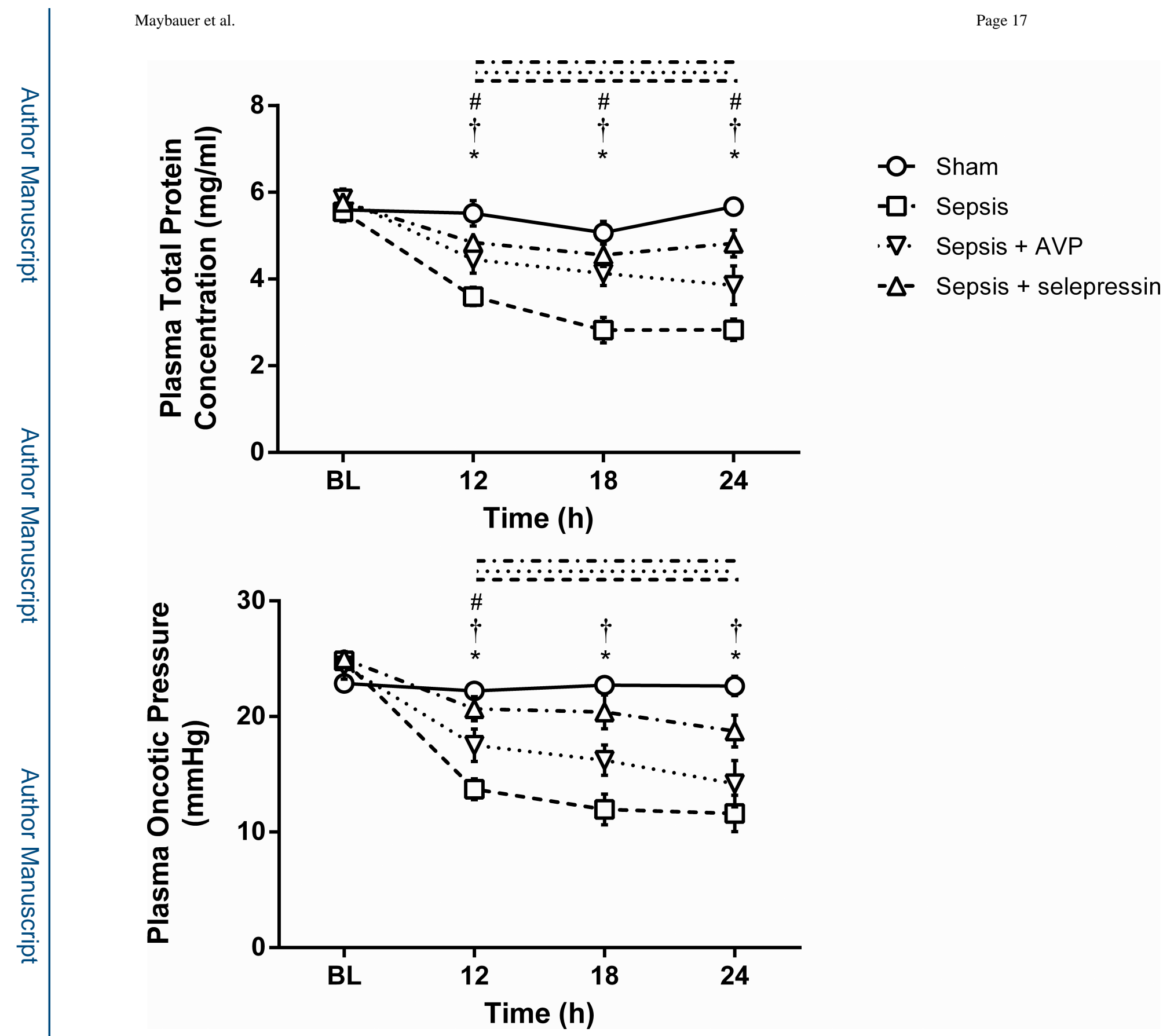

Figure 4.

Effect of AVP and selepressin on plasma total protein concentration and plasma oncotic pressure. Mean \pm SEM are shown. BL: Baseline. Sham $n=6$, Sepsis $n=1014$, Sepsis+AVP $n=810$, Sepsis + selepressin $n=9$. Significant change from BL $(P<.05)$ is indicated by the lines above the graph shape coded according to legend for study groups. *: $\mathrm{P}<.05$ for Sham vs. Sepsis; $\uparrow:$ P $<.05$ for Sepsis+selepressin vs. Sepsis; \#: P $<.05$ for Sepsis+AVP vs.

Sepsis. 


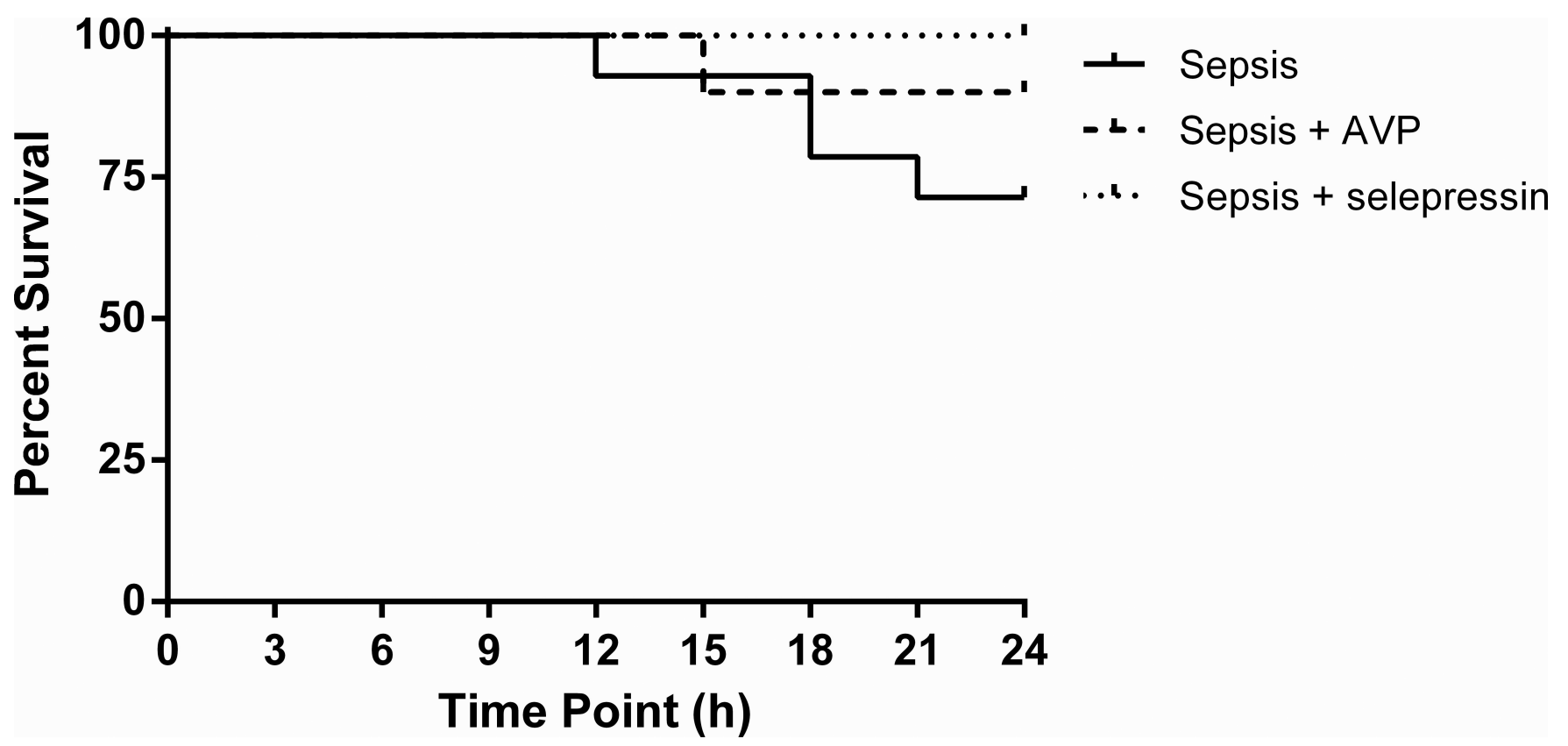

Figure 5.

Kaplan Meier survival curves. At time 0: Sepsis $(n=14)$, Sepsis+AVP ( $n=10)$, Sepsis + selepressin $(n=9)$. No significant difference between the study groups $(P=0.17$, logrank test). 


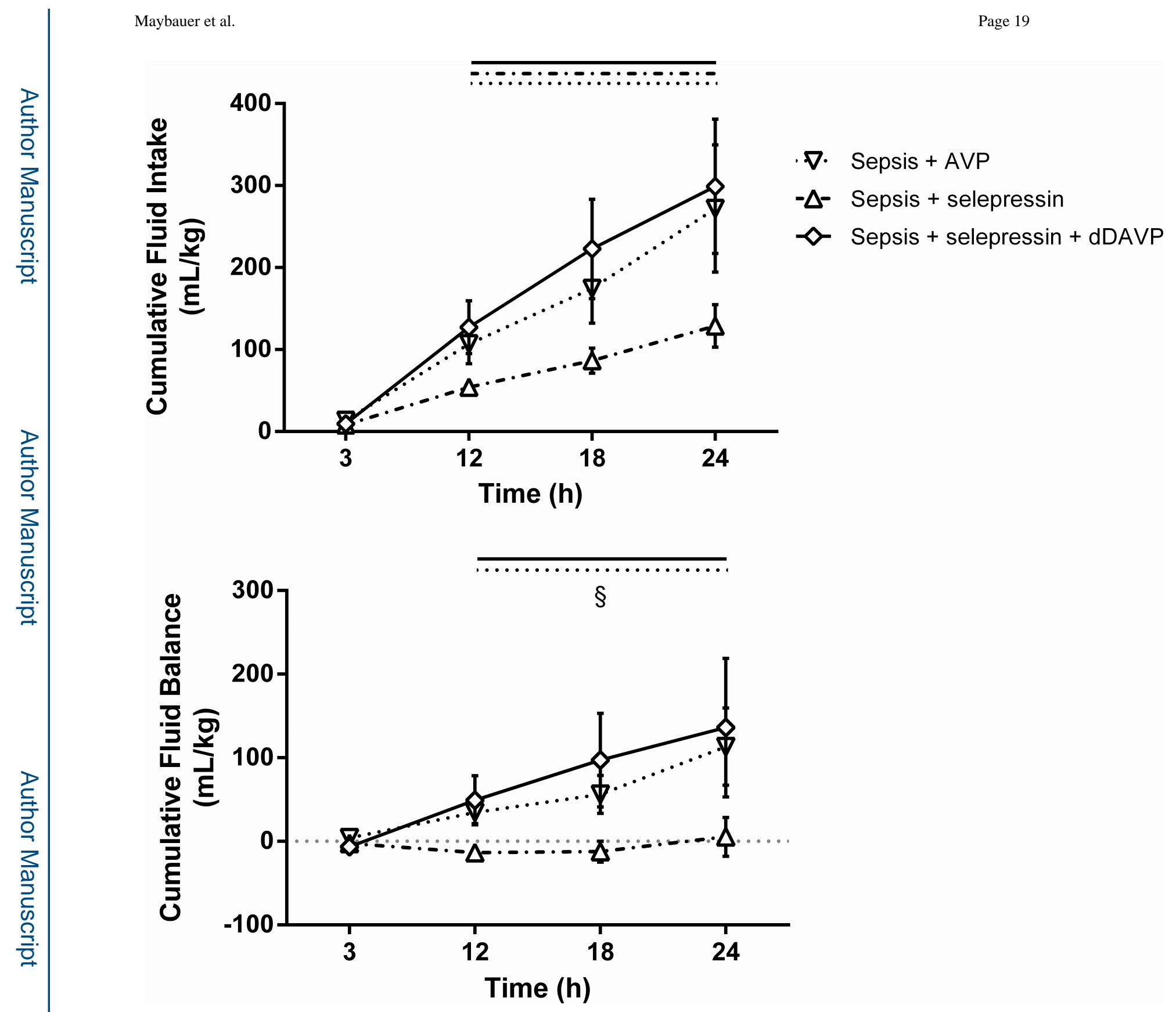

Figure 6.

Combined effect of dDAVP and selepressin on cumulative fluid intake and cumulative fluid balance. Mean \pm SEM are shown. Sepsis+AVP $n=8-10$, Sepsis+selepressin $n=9$, Sepsis + selepressin+dDAVP $n=6$. Significant change from the 3 -h time point $(\mathrm{P}<.05)$ is indicated by the lines above the graph shape coded according to legend for study groups. $\S$ : $\mathrm{P}<.05$ for Sepsis+selepressin vs. Sepsis+AVP. 

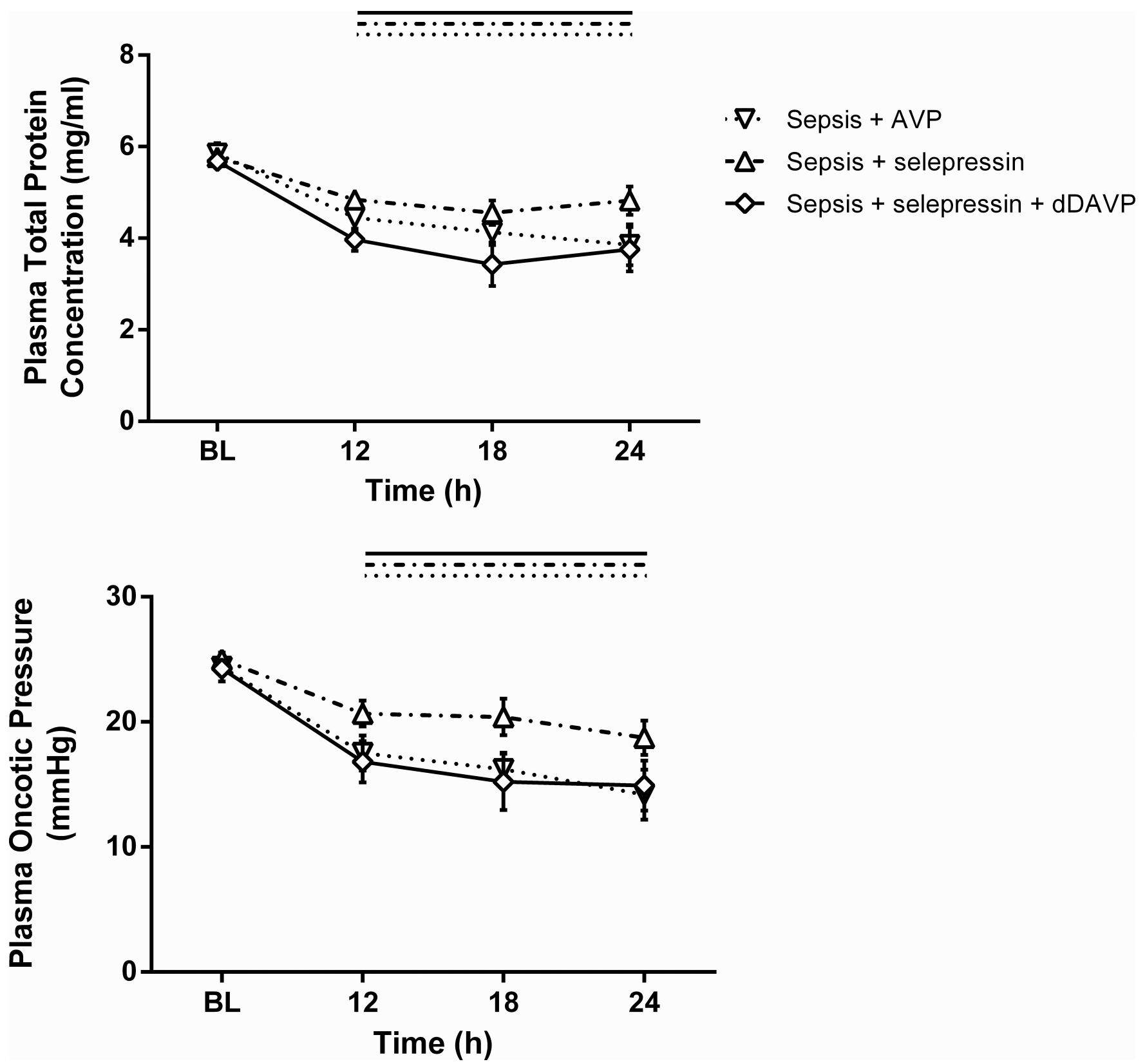

Figure 7.

Combined effect of dDAVP and selepressin on plasma total protein concentration and plasma oncotic pressure. Mean \pm SEM are shown. BL: Baseline. Sepsis+AVP $n=8-10$, Sepsis + selepressin $n=9$, Sepsis+selepressin $+d D A V P n=6$. Significant change from BL $(P$ $<.05)$ is indicated by the lines above the graph shape coded according to legend for study groups. 
Table 1

Study groups.

\begin{tabular}{lllll}
\hline Study Group & Lung Injury & Fluid Resuscitation & Vasopressor Treatment & Number of Animals \\
Sham & No & Yes & No & 6 \\
Sepsis & Yes & Yes & No & 14 \\
Sepsis + AVP & Yes & Yes & Yes & 10 \\
Sepsis + selepressin & Yes & Yes & Yes & 9 \\
Sepsis + selepressin + dDAVP & Yes & Yes & Yes & 6 \\
\hline
\end{tabular}

* Smoke inhalation injury and bacterial instillation. 


\section{Table 2}

Cardiorespiratory and related variables.

\begin{tabular}{|c|c|c|c|c|}
\hline Study Group & BL & $12 \mathrm{~h}$ & $18 \mathrm{~h}$ & $24 \mathrm{~h}$ \\
\hline \multicolumn{5}{|c|}{$\mathrm{P}_{\mathrm{a}} \mathrm{O}_{2} / \mathrm{F}_{\mathrm{i}} \mathrm{O}_{2}$ Ratio } \\
\hline Sham & $539 \pm 22$ & $539 \pm 31^{\dagger}$ & $550 \pm 33^{\dagger}$ & $565 \pm 30^{\dagger}$ \\
\hline Sepsis & $540 \pm 8$ & $123 \pm 21^{*}$ & $84 \pm 10^{*}$ & $64 \pm 9^{*}$ \\
\hline Sepsis + AVP & $527 \pm 10$ & $146 \pm 30^{*}$ & $145 \pm 30^{*}$ & $161 \pm 40^{*}$ \\
\hline Sepsis + selepressin & $523 \pm 6$ & $170 \pm 21^{*}$ & $96 \pm 21^{*}$ & $101 \pm 19^{*}$ \\
\hline \multicolumn{5}{|c|}{ Hematocrit (\% PCV) } \\
\hline Sham & $25.0 \pm 1.0$ & $22.0 \pm 1.0^{*}$ & $22.7 \pm 1.2^{*}$ & $22.3 \pm 0.9^{*}$ \\
\hline Sepsis & $25.0 \pm 1.0$ & $25.6 \pm 1.3$ & $25.4 \pm 1.4$ & $25.4 \pm 1.9$ \\
\hline Sepsis + AVP & $24.8 \pm 1.3$ & $23.4 \pm 1.2$ & $24.2 \pm 1.1$ & $25.1 \pm 1.5$ \\
\hline Sepsis + selepressin & $25.7 \pm 1.0$ & $24.2 \pm 1.4$ & $24.4 \pm 1.2$ & $25.0 \pm 0.8$ \\
\hline \multicolumn{5}{|c|}{$\mathrm{CVP}(\mathrm{mm} \mathrm{Hg})$} \\
\hline Sham & $6.7 \pm 0.8$ & $10.7 \pm 0.6^{*}$ & $10.0 \pm 0.9$ & $9.5 \pm 1.1$ \\
\hline Sepsis & $5.0 \pm 0.5$ & $11.3 \pm 1.1^{*}$ & $13.9 \pm 1.3^{*}$ & $12.9 \pm 1.1^{*}$ \\
\hline Sepsis + AVP & $6.6 \pm 0.9$ & $11.8 \pm 0.9^{*}$ & $10.7 \pm 1.0^{*}$ & $12.1 \pm 1.3^{*}$ \\
\hline Sepsis + selepressin & $7.6 \pm 1.1$ & $10.0 \pm 1.4$ & $11.3 \pm 1.6^{*}$ & $9.7 \pm 0.3$ \\
\hline \multicolumn{5}{|c|}{ LAP (mm Hg) } \\
\hline Sham & $9.5 \pm 1.3$ & $11.3 \pm 0.8$ & $11.5 \pm 1.1$ & $11.5 \pm 1.0$ \\
\hline Sepsis & $7.1 \pm 0.7$ & $13.2 \pm 1.1^{*}$ & $15.3 \pm 1.2^{*}$ & $15.7 \pm 1.5^{*}$ \\
\hline Sepsis + AVP & $8.6 \pm 0.9$ & $14.4 \pm 0.7^{*}$ & $12.9 \pm 1.2^{*}$ & $13.1 \pm 1.1^{*}$ \\
\hline Sepsis + selepressin & $8.1 \pm 0.8$ & $10.1 \pm 0.7^{\#}$ & $11.3 \pm 1.3$ & $11.3 \pm 1.1^{\dagger}$ \\
\hline \multicolumn{5}{|c|}{ Cardiac Index $\left(L \cdot \min ^{-1} \cdot \mathbf{m}^{-2}\right)$} \\
\hline Sham & $6.23 \pm 0.53$ & $5.47 \pm 0.44$ & $5.33 \pm 0.45$ & $5.47 \pm 0.36$ \\
\hline Sepsis & $5.63 \pm 0.18$ & $6.89 \pm 0.35^{*}$ & $7.04 \pm 0.50^{*}$ & $7.18 \pm 0.46^{*}$ \\
\hline Sepsis + AVP & $5.41 \pm 0.20$ & $5.79 \pm 0.41$ & $6.56 \pm 0.54$ & $5.60 \pm 0.53$ \\
\hline Sepsis + selepressin & $6.11 \pm 0.28$ & $6.18 \pm 0.41$ & $6.15 \pm 0.48$ & $5.60 \pm 0.39$ \\
\hline \multicolumn{5}{|c|}{ Vasopressor Infusion Rate $\left(\mathrm{pmol} \cdot \mathrm{kg}^{-1} \cdot \mathrm{min}^{-1}\right)$} \\
\hline Sepsis + AVP & 0 & $2.6 \pm 0.9$ & $3.7 \pm 1.4$ & $6.7 \pm 3.5$ \\
\hline Sepsis + selepressin & 0 & $6.9 \pm 2.1$ & $17.0 \pm 4.7$ & $44.1 \pm 22.2$ \\
\hline
\end{tabular}

Mean \pm SEM are tabulated. BL: Baseline. Sham $n=6$, Sepsis $n=9-14$, Sepsis + AVP $n=7-10$, Sepsis + selepressin $n=6-9$.

${ }^{*} P<.05$ vs. BL.

${ }^{\dagger} P<.05$ vs. Sepsis.

${ }_{P}^{\#}<.05$ vs. Sepsis + AVP. 